\title{
Una alternativa socialista al ethos barroco de Bolívar Echeverría
}

\author{
SAMUEL ARRIARÁN CUÉLlAR \\ Dirección de Investigación \\ Universidad Pedagógica Nacional \\ sameli@prodigy.net.mx
}

\begin{abstract}
Resumen: A partir de un análisis de las posiciones filosóficas actuales, como la hermenéutica, el posmodernismo y el multiculturalismo, se plantea una crítica del concepto de ethos barroco de Bolívar Echeverría. Sin dejar de valorar sus aportaciones, se señala que la principal insuficiencia de dicho concepto (para fundamentar una filosofía de la cultura en América Latina) reside en la dificultad de encontrar una modernidad alternativa frente a la globalización y el neoliberalismo. El concepto de ethos barroco sólo se reduciría a las condiciones históricas del siglo XVII. Hace falta explicar y definir otros tipos de modernidad, como la socialista, por lo que es necesario incorporar otros planteamientos desarrollados por autores como José Carlos Mariátegui y Adolfo Sánchez Vázquez, además del concepto complementario de neobarroco, ya desarrollado por Samuel Arriarán y Mauricio Beuchot.
\end{abstract}

Palabras clave: ethos barroco, neobarroco, mestizaje, modernidad

\begin{abstract}
From an analysis of actual philosophical positions like Hermeneutics, this article states a critics to the concept of baroque ethos of Bolívar Echeverría. Without to pass over its contributions, the author indicates that the principal inssufficiency of such a concept (in order to found a philosophy of culture in Latin America) consists in the dificulty that this concept has to arrive to an alternative modernism in oposition to the globalization and the neoliberalism, because the concept of baroque ethos only refers to the historical conditions of XVII century. It is necesary to explain and define another class of modernism like socialist modernism. For this reasons, it must incorporates another statemens like those developed for authors like José Carlos Mariátegui and Adolfo Sánchez Vázquez, and also the complementary concept of neobaroque developed for Samuel Arriarán and Mauricio Beuchot.
\end{abstract}

Key words: baroque ethos, neobaroque, hybridism, modernism

Bolívar Echeverría sostiene que la cultura se puede definir filosóficamente como cultivo crítico de la identidad. Esta definición se opone tanto a los enfoques conservadores que, en nombre de la tradición, únicamente legitiman posiciones profundamente racistas, como a aquellos otros de raíz liberal que, en nombre del universalismo, legitiman la uniformidad, la homogeneización y la integración cultural. La definición de cultura que formula este autor intenta salir del falso dilema entre universalismo o particularismo, a partir de una reelaboración de la teoría del entrecruzamiento histórico de las culturas. Esto significa replantear la cultura tomando en cuenta el proceso del mestizaje:

La historia de la cultura se muestra como un proceso de mestizaje indetenible; un proceso en el que cada forma social, para reproducirse en lo que es, ha 
intentado ser otra, cuestionarse a sí misma [... ]. El culto a la "tolerancia" que los estados occidentales de la época de la globalización tratan de infundir en sus poblaciones no es suficiente para ocultar el substancialismo profundamente racista de su autodefinición cultural. "Tolerar" significa "soportar", "permitir", es decir, simplemente "no agredir" (por lo menos aquí y por lo pronto) a los otros; no significa, como ha sido el verdadero método de la historia de la cultura (redescubierto para la modernidad por la Malinche mexicana en el siglo XVI) "abrirse" a ellos y retarlos a que ellos también "se abran". ${ }^{1}$

Para llegar a esta definición original, el autor ha atravesado un largo camino que expone en una serie de lecciones impartidas durante más de veinte años en la Facultad de Filosofía y Letras de la UNAM. En estas lecciones se recogen importantes ideas de autores olvidados como Karl Marx, Ernst Bloch, Henri Lefevre, Walter Benjamin y muchos otros provenientes de la rica tradición del pensamiento crítico. Con base en esos autores, Bolívar Echeverría nos invita a pensar en algunos problemas clave de la cultura en que vivimos cotidianamente. En el caso de los países latinoamericanos, ¿por qué después de cien años de dependencia y colaboración con el capitalismo mundial la vida económica no ha llegado a ser absorbida por él ni tampoco ha podido generar las condiciones para una reproducción autosustentable de la propia acumulación de capital?; ¿por qué la vida pública de América Latina, pese a una larga historia republicana, no logra incorporar la democracia moderna?

Contra las definiciones idealistas que ingenuamente sostienen que el desarrollo económico explica y determina la supraestructura, el autor sostiene la tesis de que si bien la cultura forma parte de la producción y, por tanto, no se puede negar la existencia de su base material, tampoco se ha de olvidar que tiene un papel determinante que incluso le permite en ciertos casos decidir el rumbo de la historia. Para ello retoma a Rosa Luxemburgo y su ejemplo de la sociedad rusa de 1900, que aunque no tenía en aquella época una base económica fuerte y desarrollada, presentaba ya un alto grado de desarrollo cultural que determinaba la necesidad de hacer una revolución política y social. Para fundamentar la importancia del papel de la cultura, Bolívar Echeverría intenta desarrollar una reflexión crítica frente a diversos autores que justifican, sea desde posiciones neutrales, sea de neopositivistas, la escasa o nula importancia de la cultura en la sociedad. Bolívar Echeverría nos recuerda la polémica en torno a la definición de cultura que hubo entre Sartre y Lévi-Strauss. Debido a que esta polémica vuelve hoy a plantearse, no está de más precisarla. Sartre le hizo a LéviStrauss un cuestionamiento de principio: estudiar al ser humano como si su vida en sociedad fuera la de una colmena o una colonia de hormigas equivalía a dejar fuera lo que es esencial. Para Sartre, la pretensión de la

${ }^{1}$ B. Echeverría, La definición de la cultura, p. 189. 
ciencia antropológica de Lévi-Strauss reside en una falacia: creer que hay que encontrar leyes naturales en un mundo cuya peculiaridad está justamente en ser una trascendencia del mundo natural. Al igual que sucedió con los estructuralistas como Lévi-Strauss, hoy resurgen definiciones darwinistas de la cultura. Por esta razón, la polémica sigue siendo la misma.

Por otra parte, al examinar la historia de las definiciones de la cultura en países como Francia, Alemania y el Reino Unido, el autor observa que la cultura se identificó arbitrariamente con lo "espiritual", al mismo tiempo que el proceso del desarrollo de la modernidad se identificó con el mercantilismo y la cosificación. La consecuencia de estas falsas identificaciones fue considerar las culturas tradicionales reducidas a "lo material" (lo primitivo o arcaico). De manera que, en la actualidad, llegamos incluso a formular definiciones equívocas de la cultura que únicamente justifican la dominación cultural, ya que se basan en la oposición entre la lógica de la identidad (que equivaldría a ser racional, "culto" o "civilizado", es decir, europeo occidental) y la lógica de la diferencia (equivalente a lo extraño, lo primitivo o lo irracional). El romanticismo intentó en su tiempo invertir estos valores; sin embargo, volvió a predominar la tradición ilustrada, pero con otro ropaje (el de la ciencia y la racionalidad instrumental). Intentando salir de este falso dilema (que separa y opone lo espiritual a lo material), Bolívar Echeverría desarrolla la idea de una complementación de la teoría de la producción con la semiótica. El proceso de producción y consumo no es otra cosa que un proceso semiótico. El ser del lenguaje es lo político (lo que constituye propiamente la dimensión cultural, diferente de la dimensión de la naturaleza; el carácter político del animal humano es lo que hace de él un ser semiótico). Partiendo de la identidad entre producción económica y producción simbólica, y basándose en la teoría de algunos lingüistas como Roman Jakobson, el autor examina las razones por las cuales la humanidad desarrolló un tipo de sociedad a partir de la prioridad de la función referencial (es decir, a partir de una política de desarrollo social exclusivamente en función del racionalismo y de las necesidades de una sociedad industrial productivista):

Ahora que las otras sociedades terminan de extinguirse, barridas por la marcha arrolladora de la modernidad, las que sí nos son conocidas y que han seguido de un modo u otro, con mayor o menor éxito, la línea del progreso, se nos revelan como sociedades que eligieron subordinar el conjunto de su actividad vital a la fase productiva de la misma; sociedades que se han hecho a sí mismas concentrándose obsesivamente en el momento de la consecución del producto [...]. Son sociedades referencialistas o contextualistas, cuyo lenguaje tiende a hacer que todas las funciones del proceso comunicativo giren en torno a aquella función que acompaña al otear en el paisaje la presa ambicionada. ${ }^{2}$

${ }^{2}$ Ibid., p. 141.

Diánoia, vol. XLIX, no. 53 (noviembre 2004). 
Aquí reside el mérito de Bolívar Echeverría, en hacer, de manera original y creativa, interesantes extrapolaciones para explicar la conexión de la cultura con la modernidad. En este sentido, nos invita a reflexionar en torno a la idea de que una definición no equívoca de cultura no debería reducirla a su función referencial (reprimiendo las otras expresiones humanas, como las pasiones, y aquellas otras vías de relación comunicativa, como el erotismo, vinculadas sobre todo con el cuerpo). El predominio de la razón, lo mental y lo cognitivo únicamente legitima la configuración de la cultura productivista y mercantil de la modernidad capitalista. Nos encontramos, entonces, con la idea de que dicha cultura no es "La Cultura" (así, con mayúsculas), sino solamente un modo particular o una concreción histórica de ella. Hay otras modernidades históricas que no reproducen la cultura en función de sus necesidades de instrumentalización de la naturaleza, de la ciencia y de la tecnología.

El autor justificadamente pone énfasis en el relativismo cultural al señalar el valor de las diferencias y de las particularidades culturales. Esto no significa negar la universalidad, sino la homogeneización forzada con fines de mercantilización (somos universales porque somos diferentes, no porque somos iguales). De esta manera, Bolívar Echeverría pone las bases para introducir un concepto de otro tipo de modernidad basado en el ethos barroco, frente a la cultura del capitalismo (defectuosa, según él, justamente por su carácter homogeneizante, univocista, referencialista y productivista). El siglo XVII de América Latina, como situación cultural de mestizaje, sirve para entender de qué manera surgió el ethos barroco como una nueva cultura que sintetizó las culturas de Oriente y Occidente:

En el siglo XVII americano, en medio y a partir de las miserias dejadas por el siglo de la conquista ibérica, el "encuentro de los mundos" inaugura, por iniciativa de los americanos, una "empresa histórica mestiza", la de reconstruir (que no prolongar) en América la civilización europea. Es una empresa a primera vista imposible, pues debe "cuadrar el círculo", poner en concordia dos identidades provenientes de la elección, ya en tiempos arcaicos, de dos vías de concretización contrapuestas, la de Oriente y de Occidente. Pero es una empresa que, aunque haya avanzado "por el lado malo" (como decía Hegel que avanza la historia), ha demostrado que es la única que puede guiar a una sociedad moderna diferente de la establecida. ${ }^{3}$

Así llegamos a la redefinición filosófica de cultura que plantea Bolívar Echeverría. La cultura como cultivo crítico de la identidad no equivale únicamente a conservar o innovar (innovar por innovar es tan estéril como conservar sólo por conservar, tal como sucedió con las vanguardias artísticas y políticas del siglo xx). Contra el conservadurismo y el creacionismo,

${ }^{3}$ Ibid., p. 241. 
es mejor plantear el modo histórico conforme al cual la cultura de los países latinoamericanos hace frente a la cultura capitalista moderna. Antes de examinar más a fondo esta definición, conviene detenernos en una cuestión histórica: ¿hasta qué punto es actual dicha definición?; ¿es una alternativa viable y deseable para una filosofía de la cultura desde América Latina? Para intentar responder a esto, es necesario hacer un balance de lo que nos ofrecen hoy los nuevos enfoques de la filosofía contemporánea. Lo que predomina son, ciertamente, las nuevas definiciones de la cultura desde las perspectivas de la hermenéutica y el multiculturalismo. Podemos aceptar la tesis de que, frente al universalismo univocista, debemos rescatar otras formas de racionalidad correspondientes a culturas particulares. No es difícil aceptar el relativismo y contraponer el valor de las diferencias. Claro que tenemos cuidado de no caer en el otro extremo, es decir, en el relativismo extremo (tal como lo hacen algunas corrientes hermenéuticas de raíz nietzscheana y heideggeriana). Quizá por la falta de una posición crítica frente a estas nuevas definiciones posmodernistas, estamos ante la tarea de elaborar y desarrollar una filosofía de la cultura o una hermenéutica latinoamericana, que puede caracterizarse provisionalmente como una filosofía neobarroca (cuyas tesis he intentado proponer junto con Mauricio Beuchot en el libro Filosofía, neobarroco y multiculturalismo) que no puede dejar de estar comprometida con el cambio social. El problema es bastante complejo, ya que además de evitar el relativismo extremo (en el que caen casi todas las concepciones hermenéuticas contemporáneas), también hay que evitar las posiciones puramente teoricistas, especulativas y, por tanto, conservadoras (como las de Gianni Vattimo y Richard Rorty).

\section{Más allá de las tesis de Bolívar Echeverría}

Más que una posición filosófica latinoamericana, hay en la obra de Bolívar Echeverría un apego a las tesis de Adorno, Horkheimer y la Escuela de Frankfurt, y también de otros autores como Heidegger (especialmente, a su crítica al humanismo como antropocentrismo). El problema de Heidegger es que su crítica niega la posibilidad de la liberación del sujeto; por eso es que quizá haya en él una intención política reaccionaria. Esta intención es totalmente explícita, no sólo en su compromiso político con los nazis, sino también en el interior mismo de su concepción filosófica (de raíz ontológica y nacionalista). Si la definición de la cultura de Bolívar Echeverría intenta criticar las definiciones nacionalistas, debería también aplicarse al nacionalismo ontológico de Heidegger. Esto no significa negar en bloque toda la filosofía de Heidegger, sino sólo la parte posterior de su obra, es decir, los escritos que surgieron después de Ser y tiempo, como su Carta contra el humanismo. 
En cuanto a las tesis de Adorno y Horkheimer en torno al eclipse de la razón, resultan más acordes con una filosofía pesimista de la historia, y en consecuencia son, por su tono apocalíptico, poco convincentes. Sus ideas sobre la manipulación cultural resultan unilaterales y maniqueístas. ¿Y por qué muestran esas características? Pues porque cuando escribieron juntos la Dialéctica de la Ilustración ya estaban totalmente desencantados de todo, no sólo del socialismo. Su visión de la cultura se reducía entonces a una definición de los efectos negativos de la industria de los medios de comunicación. Al abandonar la teoría de Marx, desembocaron en el escepticismo filosófico, subestimando la actividad creadora de los receptores. Lo que no vieron Adorno y Horkheimer (tal vez porque no creían ya en el cambio social) es que en todas las culturas hay siempre un proceso de dominación y de resistencia. Lo unilateral reside, entonces, en la exclusión del aspecto de la resistencia; y lo maniqueísta, en condenar en forma apocalíptica la cultura en general. Así, veían la razón y la ciencia como pura racionalidad instrumental con fines de dominación. Su maniqueísmo reside, entonces, en no ver el lado positivo de la cultura, es decir, que la razón y la ciencia puedan cumplir alguna vez un papel liberador.

En cuanto a las tesis específicas de Bolívar Echeverría que giran en torno al ethos barroco, se pueden hacer también algunas objeciones. Más allá de haber planteado con bastante acierto los problemas básicos para redefinir la cultura, su teoría se muestra un poco limitada. Su principal aportación, sin duda, es la tesis de la modernidad barroca, resultado del proceso de mestizaje latinoamericano, como otra racionalidad diferente, aunque no totalmente opuesta, a la cultura de la modernidad capitalista. Esta tesis aparece expresada de manera amplia en los libros que ha publicado en los últimos años (y que se pueden convertir en referentes indispensables para refundar la filosofía en América Latina). ${ }^{4}$

La modernidad puede verse de dos maneras: como algo posible o forma ideal, y como algo realizable o concreto. La modernidad capitalista sólo es una modernidad entre otras. Es defectuosa interiormente, ya que conlleva una contradicción explosiva: libertad y represión al mismo tiempo. A la vez que nos ofrece oportunidades de mayor desarrollo individual y colectivo, reniega de ellas y se vuelve una caricatura o una burla de sí misma. Por tal razón, dice el autor:

Más o menos logradas en cada caso, las diferentes modernidades que ha conocido la época moderna, lejos de agotar la esencia de la modernidad y de cancelar así el trance de elección, decisión y realización que ella implica, han despertado en ella perspectivas cada vez más diferentes de autoafirmación y

${ }^{4}$ B. Echeverría (comp.), Modernidad, mestizaje cultural y ethos barroco, 1994 ; Las ilusiones de la modernidad, 1995; Valor de uso y utopía, 1998; La modernidad de lo barroco, 1998. 
han reavivado la necesidad de ese trance, cada cual a su manera. Las muchas modernidades, las que se generaron en siglos anteriores y las que siguen apareciendo, son figuras dotadas de vitalidad concreta porque siguen constituyéndose conflictivamente como intentos singularizados de formación de una materia que aún ahora, en tiempos que quisieran ser posmodernos, no acaba de perder su rebeldía. ${ }^{5}$

Podemos retomar esta tesis y desarrollarla por nuestra cuenta, señalando que tal contradicción explosiva no se limitó a la cultura de la modernidad capitalista, sino que se extendió a la cultura de la modernidad socialista, con su consiguiente desaparición histórica. Y en este punto se le puede formular a Bolívar Echeverría una objeción: ¿por qué no definir también la modernidad socialista? Y si no cabe definirla como otra variante histórica, diferente del capitalismo y del barroco, ¿cómo explicar, entonces, los movimientos de izquierda y las revoluciones anticapitalistas del siglo Xx? Creo que es posible definir la modernidad socialista aunque tengamos que subrayar que se trata de una modernidad frustrada. ¿Pero acaso hay alguna otra que no se haya visto frustrada históricamente? Todas las modernidades han sido experiencias frustradas; por eso la modernidad siempre es otra. Y si la modernidad socialista ha sido una experiencia que nunca se realizó, ¿por qué no ver su aspecto utópico positivo y pensar en rescatarla redefiniéndola como una racionalidad ética? Como dice Sánchez Vázquez, la utopía socialista puede rescatarse y combinarse incluso con las tradiciones de las culturas premodernas:

Pero habría que precisar que esta reivindicación de la utopía socialista en América Latina (válida también para los países occidentales, donde la modernidad capitalista ya se ha consumado y topado con un límite insalvable) tiene que tomar en cuenta en América Latina lo que advirtió Mariátegui: los elementos premodernos, indígenas, que no pueden ser destruidos ni absorbidos en nombre de la modernidad. Sólo así puede hablarse propiamente de una modernidad no capitalista, de signo socialista, para América Latina, que no sea, una vez más, un calco o una copia de Occidente. Ésa es la alternativa (por lejana que esté su reivindicación) que se ha de reivindicar. ${ }^{6}$

Si lo que actualmente vemos es la extinción de la modernidad capitalista (no sólo como forma de organización económica, sino también cultural, ya que implica una racionalidad instrumental, desligada de la ética), lo que nos queda entonces es mirar hacia la cultura que tenemos en América Latina. No se puede negar la necesidad de revalorar nuestro ethos barroco y examinar sus posibilidades de conformar otra racionalidad. En vez de una

${ }^{5}$ B. Echeverría, La definición de la cultura, p. 256.

${ }^{6}$ A. Sánchez Vázquez, El valor del socialismo, p. 138. 
visión pesimista de la cultura se nos abre una perspectiva esperanzadora, ya que se trata de otra modernidad todavía no realizada. El mestizaje ofrece la posibilidad de profundizar un horizonte cultural que impediría la catástrofe social. Frente al resurgimiento del racionalismo filosófico universalista, hay mayores razones y fundamentos históricos para replantear la definición de la cultura desde el mestizaje. Pero no basta con definir la cultura; las ideas por sí solas no cambian nada. El problema es afirmar la posibilidad de su viabilidad histórica. ¿Es el ethos barroco una alternativa real frente al capitalismo neoliberal? El desafío de la filosofía en América Latina es también el de ayudar a determinar las fuerzas y movimientos sociales para enfrentar la globalización. Mi hipótesis es que la teoría del ethos barroco de Bolívar Echeverría (liberadora al principio) no constituye una alternativa por insuficiente (se queda en el pasado y, por tanto, no se conecta con las luchas sociales por la transformación del presente). Quizá por estar adherido a los conceptos filosóficos pesimistas-nihilistas de Heidegger, Adorno y Horkheimer (en torno de la modernidad), no desarrolla suficientemente la necesidad del cambio social. Por eso es que el ethos barroco no sería una alternativa frente a la modernidad capitalista. Frente a este sistema económico y político, hace falta desarrollar una estrategia de resistencia donde el ethos barroco encuentre su sentido liberador. Para ello hace falta conectarse con la estrategia socialista.

\section{La estrategia socialista}

En la historia de las revoluciones sociales existieron, no uno, sino varios tipos de enfoques sobre la estrategia socialista (reformista, radical, etc.). Vale la pena referirse hoy, dado el impresionante resurgimiento imperial que inició el 11 de septiembre de 2001, a un enfoque olvidado del marxismo que en épocas pasadas se llamaba "antiimperialista". Las raíces de este enfoque se pueden hallar en algunos escritos en torno a la cuestión nacional de Marx y Lenin, y en América Latina, de Mariátegui, los teóricos "dependentistas", el Che Guevara y muchos otros. Se pueden rescatar estos planteamientos críticos y repensarlos en el contexto de la globalización. Frente a esta realidad, ¿tiene algo que decir la filosofía política marxista? Nadie negará que los temas de la nación y el imperialismo fueron ampliamente desarrollados en esta tradición filosófica; sin embargo, ¿son viables actualmente esos planteamientos? Según las teorías de moda, como el posmodernismo, el imperio actual no se puede entender con los conceptos de la época anterior. Los ideólogos posmodernos, no contentos con haber declarado la muerte del socialismo, se apresuran ahora a declarar la defunción del Estado-nación, al mismo tiempo que realizan una apología del imperialismo. Dado que los argumentos que son poco convincentes, conviene rescatar el pensamiento crítico. Es de elemental justicia reconocer que 
hubo importantes aportaciones de este enfoque a la teoría de la nación. Además, se puede afirmar que el actual interés por la globalización tiene en parte sus orígenes en la preocupación marxista por la evolución del capitalismo. Como dice Sánchez Vázquez, hay que entender que el imperio es propio de un sistema económico y social (el capitalismo), en el que las empresas transnacionales de Estados Unidos gozan de hegemonía.

\section{José Carlos Mariátegui}

José Carlos Mariátegui habló de la necesidad de un socialismo antiimperialista e indoamericano, ya que el principal problema social de muchos países de América Latina es el problema nacional. La aportación de Mariátegui reside, por una parte, en proponer una nueva interpretación de la realidad latinoamericana y, por otra, en ofrecer una estrategia socialista basada en dicha interpretación. La realidad que interpreta Mariátegui es la de Perú, un país atrasado, sometido al imperialismo, con una población indígena mayoritaria en condiciones de absoluta marginación social. ${ }^{7}$

Justamente, esa presencia indígena constituye para Mariátegui el problema nacional, pues al considerar que dicha presencia tiene una gran importancia para el desarrollo de una política socialista, advierte la insuficiencia del concepto de clase, razón por la que se ve en la necesidad de elaborar una nueva estrategia que no se reduzca a una lucha clasista entre burguesía y proletariado. Evidentemente, Mariátegui coincide con el paradigma de Lenin sobre la necesidad histórica de la lucha antiimperialista; pero lo interesante es que va más allá de los planteamientos leninistas al abarcar el problema indígena. Esto significa que es posible combinar el socialismo con la realidad multicultural y pluriétnica. En este sentido, cabría la posibilidad de combinar las tradiciones indígenas con la modernidad occidental. Obviamente, este tipo de marxismo se apartó del dogmatismo de la época. Para ese marxismo dogmático, positivista, cientificista (igual que para casi toda la tradición de los partidos de izquierda en América Latina), la solución al problema indígena era su desaparición mediante su integración a la cultura occidental. Desde esta perspectiva, las tradiciones culturales eran incompatibles con el desarrollo de las fuerzas productivas. Tal desarrollo implicaba precisamente sacrificar esas tradiciones, ya que constituían elementos relacionados con el atraso; pero ise puede conciliar el desarrollo de las fuerzas productivas con la realidad multicultural y pluriétnica de América Latina? Podría responderse de dos maneras: a) relativizando la idea del desarrollo lineal de la historia, y b) relativizando la idea de que el progreso implica forzosamente liquidar las tradiciones indígenas. Hoy en día está en crisis el paradigma del desarrollo de las

\footnotetext{
7 J.C. Mariátegui, Siete ensayos de interpretación de la realidad peruana.
} 
fuerzas productivas. Ésta es una cuestión que no previó Marx. Ya no se puede pensar que las fuerzas productivas tienen un desarrollo ilimitado o que pueden ser la única vía de progreso, hay que buscar otras formas de racionalidad y de organización social. En consecuencia, podemos pensar en la posibilidad de revalorar la estrategia socialista a partir de las tradiciones culturales, y no necesariamente de las necesidades del productivismo económico-industrial. Esta revaloración no contradice el pensamiento de Marx; por el contrario, coincide con sus ideas sobre la historia, pues él no pensaba que el capitalismo tuviera que darse en todas las sociedades de manera lineal e inexorable. A partir de la concepción indoamericana de Mariátegui se puede reivindicar hoy una valoración socialista de las tradiciones culturales y plantear, frente a la globalización neoliberal, otro tipo de modernidad. Esto significa buscar una concepción ética relacionada con una forma de modernidad alternativa al sistema capitalista.

\section{La teoría de la dependencia}

En los años sesenta y setenta, muchos autores de varios países latinoamericanos señalaron que la verdadera causa de nuestro subdesarrollo no estaba en los elementos tradicionales que subsistían en América Latina, sino más bien en los elementos de modernidad que imponían relaciones de dependencia entre naciones. Evidentemente, estos autores, luego descalificados como "dependentistas", estaban influidos por las obras de Rosa Luxemburgo, Bujarin, Trotsky y Lenin, y de otros contemporáneos como Paul Baran, Paul Sweezy, Samir Amin, Arghiri Emmanuel y Charles Bettelheim, lo cual los presentaba como críticos del sistema capitalista desde posiciones cercanas a la teoría marxista. En efecto, los "dependentistas" comenzaron sus estudios destacando las hipótesis sobre el "intercambio desigual" y sobre el "deterioro de los términos de intercambio" (conceptos que numerosos marxistas empleaban entonces para explicar los problemas del comercio internacional y sus implicaciones políticas). En este sentido, merecen recordarse los trabajos de Arghiri Emmanuel y Charles Bettelheim, en los que se explica que el gran desarrollo y el bienestar económico de los países europeos tienen su raíz en la explotación ejercida sobre los países dependientes. Esa explotación ha posibilitado los elevados salarios de la población europea con la consiguiente pérdida de solidaridad con los países subdesarrollados. ${ }^{8}$

Si bien es cierto que no todos desarrollaron hipótesis tan fecundas, problematizaron a su modo la relación existente entre las naciones y la relación del Estado nacional con las clases sociales en América Latina. Así, el pensamiento social latinoamericano, durante el periodo de 1960 a 1970,

\footnotetext{
${ }^{8}$ A. Emmanuel et al., Imperialismo y comercio internacional (el intercambio desigual).
} 
intentó responder por lo menos a tres cuestiones fundamentales: a) ¿qué relación existe entre lo interno (el Estado nacional) y lo externo (el mercado mundial)?, ¿es obligatoria la incorporación de la dimensión externa para que tengan sentido las relaciones internas, entendidas estas últimas como relaciones de dependencia?; b) ¿tiene un fundamento de clase la relación entre naciones?; c) ¿pueden suprimirse las premisas nacionales para la explicación de las luchas de clases en América Latina?

Hay un fundamento de clase en la relación entre naciones, pero también toda lucha de clases tiene un componente nacional. En el caso de los autores latinoamericanos, el surgimiento de esta problemática respondió a la coyuntura de mediados de la década de los sesenta. En este sentido, hay que destacar los siguientes hechos: 1) las elevadas tasas de empobrecimiento extremo de las masas y del desempleo; 2) la aparición de dictaduras militares; 3) el fracaso de alternativas populistas. En este contexto histórico no es difícil comprender el esfuerzo de los "dependentistas" por analizar el carácter estructural de los problemas latinoamericanos. Según ellos, el desempleo y la marginación de los sectores populares responde a los efectos de la integración de América Latina a la economía mundial. Su mérito indiscutible fue introducir el análisis del factor externo para dar sentido a la explicación de los problemas internos. Como decía Ruy Mauro Marini: "es a partir de entonces que se configura la dependencia entendida como una relación de subordinación entre naciones formalmente independientes, en cuyo marco las relaciones de producción de las naciones subordinadas son modificadas o recreadas para asegurar la reproducción ampliada de la dependencia". ${ }^{9}$ En palabras de André Gunder Frank: "la relación colonial por lo tanto determina el modo de producción, la estructura de clase, los intereses de la burguesía y la política del subdesarrollo". ${ }^{10}$

Ciertamente, la teoría de la dependencia acabó por reducir el análisis unilateralmente al factor externo. No se puede negar que, posteriormente, esta teoría se volvió mecanicista, adialéctica y acabó por deducirlo todo de nuestra articulación con la economía mundial. Pese a estas limitaciones, cumplió un papel positivo en el desarrollo de un pensamiento adecuado a la realidad de América Latina, ya que motivó la preocupación por las formas de "ayuda exterior" y el papel de las empresas transnacionales.

Después de la teoría de la dependencia y a raíz del "derrumbe del socialismo real", casi nadie habla del imperialismo. Autores como Néstor García Canclini argumentan que "el cosmopolitismo actual y las nuevas dependencias se entienden poco con el vocabulario de la época en que hablába-

\footnotetext{
${ }^{9}$ Ruy Mauro Marini, Dialéctica de la dependencia, p. 100.

${ }^{10}$ Luis Vitale, André Gunder Frank et al., Feudalismo, capitalismo y subdesarrollo.
} 
mos de imperialismo y nación". ${ }^{11}$ Sin embargo, hoy, cuando se manifiesta agresivamente el imperialismo estadunidense, resulta necesario revalorar algunas tesis de los dependentistas. Esto no quiere decir que haya que rescatarlos en bloque o que haya que repetir al pie de la letra todo lo que escribieron. Lo que hace falta es pensar los nuevos problemas de la realidad social (que, por cierto, José Gaos señalaba que ésa era la principal tarea de la filosofía, es decir, no tanto reflexionar sobre temas trascendentes o sistemáticos, sino sobre problemas de las circunstancias, de resolución social urgente).

\section{Conclusión}

Volviendo al concepto de ethos barroco de Bolívar Echeverría, se puede concluir asegurando que no todo en él es negativo. Es posible y útil retomar ese planteamiento y tratar de complementarlo con algunas ideas desarrolladas por autores como Mariátegui y los dependentistas. Quizá la principal carencia metodológica es que hace falta subrayar hoy el carácter económico y político de América Latina, fuertemente sujeta a las determinaciones del imperio. Si queremos comprender la realidad actual, hace falta recurrir, no ya al concepto de barroco en su formulación inicial (que tal como lo postula Bolívar Echeverría, se reduce al siglo XVII) sino a las condiciones impuestas por el proceso de la globalización y de la posmodernidad. En América Latina se puede redefinir la posmodernidad complementando el concepto del ethos barroco de Bolívar Echeverría con el concepto de neobarroco. Este concepto permite determinar un criterio filosófico para explicar nuestro proceso cultural en la actualidad. El problema del concepto de ethos barroco de Bolívar Echeverría radica en que, si bien resulta atractivo por su poder explicativo, no llega al presente. Hoy se trata de buscar, ante todo, una estrategia de resistencia en las condiciones históricas de la globalización y el dominio neoliberal. Aquí saltan las limitaciones del concepto del ethos barroco, ya que no puede indicar una política de transformación de la sociedad actual. Bolívar Echeverría es escéptico frente al concepto de neobarroco como una posmodernidad alternativa; según su argumentación, no es útil, ya que está conectado con la coyuntura de las vanguardias europeas del siglo $\mathrm{XX}$, y como estamos en el momento de la posvanguardia o de la muerte de las vanguardias, resultaría inaceptable o poco útil. A mi modo de ver, el neobarroco es un concepto que no necesariamente se relaciona con las vanguardias europeas; ésa es solamente una tesis de Omar Calabrese. ${ }^{12}$ Para el caso de América Latina resulta vital encontrar una salida liberadora. El neobarroco se puede conectar con la situación posmoderna en que vivimos, pero no se trata de

${ }^{11}$ Néstor García Canclini, Latinoamericanos buscando lugar en este siglo, p. 54.

12 Omar Calabrese, La era neobarroca, 1989. 
la posmodernidad entendida de manera nihilista: se trata de otra posmodernidad como mestizaje positivo entre las prácticas culturales, las imágenes y los símbolos de la modernidad occidental y las tradiciones culturales locales.

\section{BIBLIOGRAFÍA}

Alberro, Solange, "Imagen y fiesta barroca: Nueva España, siglos XVI-XVII", en Petra Schumm (comp.), Barrocos y modernos. Nuevos caminos en la investigación del Barroco iberoamericano, Vervuert/Iberoamericana, Fráncfort del Meno/Madrid, 1998, pp. 33-48.

Arriarán, Samuel, Filosofía de la posmodernidad, UnAM, México, 1997.

Arriarán, Samuel y Mauricio Beuchot, Filosofía, neobarroco y multiculturalismo, Ítaca, México, 1999.

Borón, Atilio, Imperio. Imperialismo. Una lectura crítica de Michael Hardt y Antonio Negri, Clacso, Buenos Aires, 2002.

Calabrese, Omar, La era neobarroca, Cátedra, Madrid, 1989.

Echeverría, Bolívar, La definición de la cultura, Ítaca, México, 2001.

—_, La modernidad de lo barroco, Era, México, 1999.

__ Las ilusiones de la modernidad, UNAM-El Equilibrista, México, 1995.

(comp.), Modernidad, mestizaje cultural y ethos barroco, UNAM-El Equilibrista, México, 1994.

— - Valor de uso y utopía, Siglo XXI, México, 1998.

Emmanuel, A. et al., Imperialismo y comercio internacional (el intercambio desigual), Cuadernos de Pasado y Presente, México, 1971.

Gaos, José, En torno a la filosofía mexicana, Alianza, México, 1980.

García Canclini, Néstor, Latinoamericanos buscando lugar en este siglo, Paidós, Buenos Aires, 2002.

García Canclini, Néstor (coord.), Culturas en globalización. América Latina-EuropaEstados Unidos: libre comercio e integración, Nueva Sociedad, Caracas, 1996.

Gruzinski, Serge, El pensamiento mestizo, trad. Enrique Folch González, Paidós, México, 2000.

Hatzfeld, Helmut, Estudios sobre el Barroco, trad. Ángela Figuera, Gredos, Madrid, 1973.

Lezama Lima, José, La expresión americana, Fondo de Cultura Económica, México, 1993.

Maravall, José Antonio, La cultura del barroco, Ariel, Barcelona, 1990.

Mariátegui, José Carlos, Siete ensayos sobre la realidad peruana, Biblioteca Amauta, Lima, 1995.

Marini, Ruy Mauro, Dialéctica de la dependencia, Era, México, 1973.

Sánchez Vázquez, Adolfo, El valor del socialismo, Ítaca, México, 2000.

Sarduy, Severo, "El barroco y el neobarroco", en César Fernández (coord.), América Latina en su literatura, México, Siglo XXI/UnESCO, pp. 167-184.

Schumm (comp.), Barrocos y modernos. Nuevos caminos en la investigación del Barroco iberoamericano, Vervuert/Iberoamericana, Fráncfort del Meno/Madrid, 1998. 
Villoro, Luis, Estado plural, pluralidad de culturas, Paidós-UnAM, México,1998.

Vitale, Luis, André Gunder Frank et al., Feudalismo, capitalismo y subdesarrollo, Akal, Madrid, 1977.

Zea, Leopoldo, La filosofía americana como filosofía sin más, Siglo XXI, México, 1980.

Recibido el 26 de abril de 2004; aceptado el 31 de mayo de 2004. 